\title{
Qualitative Analysis of Family-centered Care for Children with Cancer in Palliative Wards: An Evaluation of Needs and Barriers in Resource-limited Settings
}

\author{
Sumarti Endah Purnamaningsih Maria Margaretha ${ }^{1,2 *}$ (D) , Sri Mulatsih ${ }^{3}$, Christantie Effendy ${ }^{4}$, Hari Kusnanto ${ }^{5}$ \\ ${ }^{1}$ Department of Nursing, Faculty of Medicine, Public Health and Nursing, Gadjah Mada University, Yogyakarta, Indonesia; \\ ${ }^{2}$ Department of Nursing, Faculty Member, Poltekes Karya Husada, Yogyakarta, Indonesia; ${ }^{3}$ Department of Nursing, Faculty \\ of Medicine, Public Health and Nursing, Gadjah Mada University, Yogyakarta, Indonesia; ${ }^{4}$ Departement of Surgery Nursing, \\ Faculty of Medicine, Public Health and Nursing, Gadjah Mada University, Yogyakarta, Indonesia; ${ }^{5}$ Departement of Family \\ Medicine Community, Faculty of Medicine, Public Health and Nursing, Gadjah Mada University, Yogyakarta, Indonesia
}

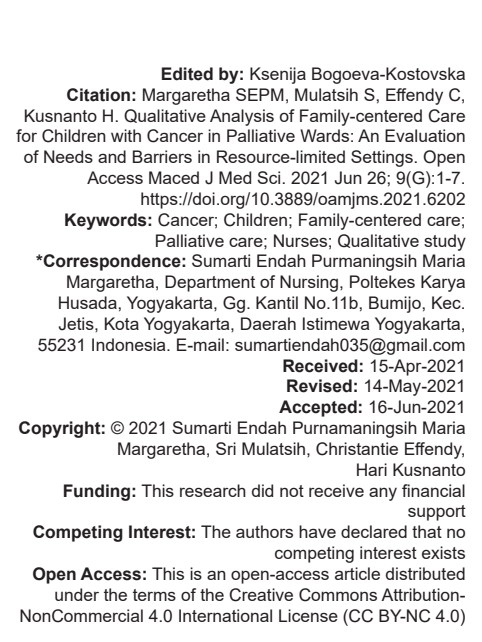

Abstract

BACKGROUND: Many children with cancer are faced with fatal diagnosis and unbearable pain, and palliative care is highly needed. In Indonesia, the provision of palliative care is only accessible in a few major cities where most cancer treatment facilities are located and development has been slow. While, the implementation of family center care identified a number of challenges related to family empowerment to be included in the development and implementation of interventions.

AIM: This study aimed to assess the perspectives of nurses regarding family-centered treatment in Indonesia's palliative wards for children with cancer.

METHODS: A qualitative approach to content analysis was employed. The study participants were 10 primary nurses in pediatric units who worked with cancer patients regularly. These participants were purposefully chosen The interview session included 10 study participants. Participants' work experience ranged from 2 to 11 years, and their age ranged from 27 to 51 years. Data were collected through face-to-face, semi-structured interviews that lasted for an average of 30-45 min. The interviews were performed to explore the participants' understanding abou the definition of family-centered palliative care, including the needs and obstacles to implementation. These were analyzed using content analysis methodology that includes five main segments: Introduction, coding, theme creation, thematic classification, and reporting.

RESULTS: The themes from the study included an appreciation of palliative and family-centered care (FCC) palliative care capability and FCC, and multidisciplinary cooperation under three principles concerning needs and barriers.

CONCLUSION: Integrating FCC approaches in providing palliative care for children with cancer as well as the resources required for such programs to be implemented by hospital management in working toward improved quality care for patients. Communication and continuity of care remain a challenge; training and equipping clinicians with skills and confidence to carry out FCC approaches and palliative care for children with cancer can aid in this process.

\section{Introduction}

While there is progress in reducing the global burden of childhood cancers, the prevalence of new cancers in low- and middle-income countries (LMICs) is increasingly growing [1]. About $80 \%$ of the global burden of cancer currently lies in countries with just $5 \%$ of the medical services available [2]. Most cancers occur in childhood in conditions were delayed diagnosis and insufficient access to treatment exacerbate essential resource constraints [3]. Most cancer deaths - up by twothirds - occur in LMICs [4]. Many children with cancer are left with terminal diagnoses and needless pain in resourcepoor settings worldwide [5], [6]. Cancer is a leading cause for $20-30 \%$ of children's cases of palliative care [7], [8].
The World Health Organization (WHO) states that palliative care is an integral aspect of the minimum health-care plan (Conor, 2014). Pediatric palliative care (PPC) is an active and comprehensive care program intended to reduce and relieve suffering and enhance the quality of life of children and their families [9], [10], [11]. Empirical studies have shown that quality of life of pediatric patients with cancer and their family can be improved through prevention and reduction of family and children trauma through the implementation of caring and honest touch, symptom relief, and psychosocial treatment through palliative care [12]. However, children with palliative care remain noticeably absent in developing countries; an estimated 1.2 million children worldwide demand palliative care, and the large percentage (98\%) live in LMICs [13], [14]. 
As children's cancer treatment in LMICs addresses complications, it has its obstacles to PPC-barriers that are multidimensional, complicated, and inadequately understood. Financial and infrastructure obstacles are the subject of low-resource settings [14], [15]; few have written about broader, more complex barriers or possible solutions. Additional multidisciplinary studies are necessary to discover potential alternatives and offer policy changes to incorporate palliative care effectively in the end.

Family-centered care (FCC) is characterized as the delivery of services that revolve around family integration in the creation and implementation of interventions; it represents a family-professional partnership [16]. The FCC is based on cooperation between patients, families, physicians, nurses, and other practitioners in the field of clinical care, as well as on the preparation, implementation, and assessment of health care, and on the training of health professionals and in research [17]. Conversely, Perrin et al. characterized FCC as an integrated family-friendly health care, education, and social services system that allows for structured, community-wide care [18]. The universal purpose of the FCC models is to establish and execute patient care programs within the family context. To facilitate this objective, FCC models include cooperation between family members and health-care providers, awareness of family backgrounds, education for patients, families and health professionals, and committed policies and procedures [19]. Nurses play a major role in the successful implementation of the FCC. They are also the first point of touch for the families of patients and are a constant presence at the bedside, which helps nurses to determine the capacity of family members to cope, emotional states, desires, and expectations for information [20], [21]. Nurses are committed to ensuring that the needs of the entire family are met and act as educators by interpreting medical knowledge and promoting contact between physicians and the family [22].

In the context of palliative care, familycentered interventions can reduce the burden of care in families during a crisis [23]. In palliative care, the core values or primary principles that underpin palliative and bereavement care are compassion, dedication to delivering palliative/bereavement care, dignity, integrity, respect, exchange of knowledge, parenting, and teamwork [23]. Furthermore, there is a strong understanding that patients and families are an integral part of the health-care team, and both work together to plan and implement palliative and/ or bereavement care [24]. Other researchers argued that family-based care provides an opportunity to help families and improves a working relationship between the patient, family, and health practitioners in the endof-life care sector [19]. Gilmer (2002) describes FCC as a continuous consistency in addressing patients with terminal conditions, family, and community needs through interdisciplinary collaboration [25]. Specifically, collaboration with medical personnel and the patient and family, ongoing monitoring of patient and family needs, development-oriented interventions, and functional support during hospital and home care transition times are the focus areas where holistic treatment can be improved by a palliative care model [12], [26]. It is also necessary to include the family in the care plan and to understand that each family has different approaches to palliative and bereavement care.

In Indonesia, palliative care is not a new issue that has been improving palliative care since 1992 and developed a palliative care policy launched by the Indonesian Ministry of Health in 2007. However, palliative care services are only accessible in a few major cities where most cancer treatment facilities are located and development has been slow across city [27]. Rochmawati et al. [28] reviewed the facilitation factors that promote the provision of palliative care in Indonesia, including a tradition of strong family support, limited awareness of palliative care among health-care professionals, the difficult geography of Indonesia, and limited access to opioid medicines. While, the implementation of the FCC identified a number of challenges related to family empowerment to be included in the development and implementation of interventions, including lack of family knowledge about their child's condition, health professionals viewed as superior, and a strong cultural issue [29]. Considering the above condition, this study aimed to investigate the profound adoption of FCC in Indonesia's palliative wards for children with cancer.

\section{Materials and Methods}

\section{Design and setting}

A qualitative content analysis approach was selected using an interpretive model to investigate the implementation of family-centered treatment in referral hospital in Yogyakarta, Indonesia, that treats or deals with cancer patients daily. The method of content analysis provides a direct insight into experiences correlated with qualitative research [30]; it was considered appropriate for the present qualitative study. However, from interaction with participants, most of them ever joined seminar regarding palliative care in Indonesia and it was clear that there were no formal palliative care mechanisms or systems to direct healthcare professional in caring for children with cancer at the time the study was conducted; instead, participants discussed care delivery from their viewpoints.

In addition, in 2007, the Minister of Health announced a national policy on palliative care. However, the policy has not been fully implemented in the 
health-care system due to the absence of palliative care guidelines and standards, a proper referral system, and sufficient funding. In this study, we choose nurses as participants due to they are also the first point of touch for the families of patients and are a constant presence at the bedside, which helps nurses to determine the capacity of family members to cope, emotional states, desires and expectations for information [20], [21].

In pediatric oncology wards of the referral hospital in Yogyakarta, we interviewed register nurse who provide direct and regular treated children with cancer. For this research, qualitative interviews were most fitting, as they allow respondents to discuss the topics posed by the questions [31]. We also recruited a large city primary care unit that could represent Indonesia's most populated provinces to understand the level of referrals and service provision. Yogyakarta is one of the provinces where palliative care centers are not yet open. Approval of ethics was obtained from the Faculty of Medicine's Ethics Committee, Gadjah Mada University.

\section{Participants}

The study participants were 10 primary nurses in palliative wards and units who cared for or worked with cancer patients regularly. These participants were purposefully chosen. The eligibility criteria for taking part in the study included nurses in cancer patient care units. At each initial contact, participants were informed about the nature and intent of the study and its benefits. Face-to-face interviews were performed in 2020 to assess the participants' understanding about the definition of family-centered palliative care, including the needs and obstacles to implementation. Written inform consent was obtained from each participant prior data collection.

The interview included face-to-face and online sessions with six and four primary nurses as study participants, respectively. Their years of work experience ranged from 2 to 11 years, and their age ranged from 27 to 51 years. Table 1 shows information on participants' demographic data.

\section{Data collection}

For this analysis, data were collected through face-to-face, semi-structured interviews for an average of $30-45 \mathrm{~min}$. All interviews were performed in the workplace of each participant. Participants were contacted by phone or email and were explained the aims and methods of the study by the primary researcher. They were required to provide written informed consent. The research sought feedback and perspectives from nurses, independent of their expertise, or prior contact with palliative care. Interviews were performed until data saturation was achieved at 10 participants [32].
Table 1: Primary nurses' demographics $(n=10)$

\begin{tabular}{llllll}
\hline Participants & Gender & Age & Marital status & $\begin{array}{l}\text { Professional } \\
\text { qualification }\end{array}$ & $\begin{array}{l}\text { Years of } \\
\text { experience }\end{array}$ \\
\hline P1 & Female & 28 & Married & BSN, RN & 3.5 \\
P2 & Female & 32 & Married & BSN, RN & 5 \\
P3 & Female & 39 & Married & BSN, RN & 7 \\
P4 & Female & 27 & Single & BSN, RN & 2 \\
P5 & Female & 31 & Married & BSN, RN & 6 \\
P6 & Female & 35 & Married & BSN, RN & 6 \\
P7 & Male & 38 & Married & BSN, RN & 7 \\
P8 & Male & 43 & Married & BSN, RN & 8 \\
P9 & Female & 50 & Married & BSN, RN & 11 \\
P10 & Male & 31 & Married & BSN, RN & 3 \\
\hline
\end{tabular}

A semi-structured topic guide, inspired by the literature and local palliative care experience, was developed. The discussion began with general questions about the nurse's experience in caring for and treating children with cancer, specifically on palliative care services and FCC; and their thoughts and views on the provision. The interviewer followed the guided topics and used this approach to obtain clarity; however, the approached did not contribute to the definitions of terms. We discussed and assessed the nature of palliative care with the respondents without providing them its description from the $\mathrm{WHO}$, which the research used.

The interviews were audiotaped, with the respondents' permission. Of the 10 participants, four were interviewed face to face and six were interviewed individually (online) through Zoom application. The interviews were conducted by team members in Bahasa Indonesia and transcribed in verbatim. The research team reviewed the consistency of these transcripts for the accuracy of the translation.

\section{Data analysis}

For individual interviews with primary nurses, the audiotaped recordings were transcribed in verbatim. These were analyzed using content analysis, which includes five main segments: Familiarization, coding, theme creation, thematic description, and reporting [30], [33], [34]. Data were analyzed after the initial interviews. Results of the study were analyzed, and lists of questions were created for focus groups and interviews to justify or endorse responses. To obtain a better understanding of the results, each transcribed interview was read many times. The second stage involved describing the major topics, principles, and themes. To show the code merges, data were analyzed line by line. The condensing units of meaning were abstracted and labeled with symbols, forming the substance of the attestation. Several codes were related in the third stage according to differences and similarities and were sorted into corresponding subcategories and categories (Table 2). This study was formulated in terms of the main concepts that emerged from conversations in the focus groups and patient interviews. Two participants examined the emerging themes. All data were analyzed using NVivo 11, a qualitative data analysis program. 


\section{Results}

The themes that emerged from the study were collected based on palliative care under three categories concerning the needs and challenges in the implementation of family-centered treatment (Table 2). Some themes that demonstrate findings by primary nurses are discussed in detail.

\section{Theme 1: Knowledge of palliative and FCC}

Awareness of palliative and FCC was the first trend arising from the data review. Participants noted obstacles to FCC and palliative care such as limited information regarding the introduction of palliative and FCC, inconsistency in deciding the classification of patients, unsatisfactory services as viewed by nurses' self-evaluation, and lack of palliative and FCC awareness.

"Patients who are no longer responding to chemotherapy are patients who are eligible for palliative care." (P2)

\section{"I don't know about the FCC." (P3)}

"So, whether the FCC is a new intervention, I don't really understand (smile)." (P3)

"FCC is a family-focused treatment, right?" (P5)

\section{Theme 2: Ability to provide palliative and}

\section{FCC}

Some nurses believed that by delivering palliative care and integrating it with a FCC approach is needed. In addition, nurses wanted to strengthen their ability to meet the needs of children with cancer treatment. They also wanted to develop their leadership skills to work as team and coordination in providing care in the context of palliative care and FCC, and share their understanding and methods to achieve greater benefits.

"In terms of patients, there are many patients, there are those who cry, some can be cooperative, some don't want to (smile), some maybe have a psychologically disturbed." (P1)

"In terms of parents, there are parents who are complaining, there are parents who are obedient, there are those who are basically cooperative." (P3)

"A palliative patient has been declared dead; our support is by, for example, finding an ambulance." (P5)

"We will still convey it to his family, then later in the hospital. Then, we must still convey it to senior and manager also hospital management." (P10)

\section{Theme 3: Multidisciplinary collaboration}

The primary nurses reported the value of multidisciplinary teamwork to provide higher quality care. Multidisciplinary cooperation included collaboration with other health-care professionals, participation of other professions in delivering treatment, recognition of health-care professional's role and function, respect to others, and adaptation to work setting.

"So, it is necessary, consultation or with a psychologist, some have reached a psychiatrist." (P7)

"Every day, there are meetings between doctors and nurses to discuss patients." (P2)

"Collaboration both with family and with other health workers as well, we will try to work together with such collaboration." (P4)

"By means of nutrition, the nutrition that makes the program, for example, the doctor calculates this fluid requirement." (P5)

Table 2: Results of interviews content analysis including general theme, themes, and subthemes of primary nurses

\begin{tabular}{|c|c|c|}
\hline Theme & Sub-theme & Example of participants' answers \\
\hline $\begin{array}{l}\text { Knowledge of palliative care } \\
\text { and family-centered care }\end{array}$ & $\begin{array}{l}\text { - Limitation in implementation of palliative care and } \\
\text { family-centered care } \\
\text { - Discrepancy in determine patients' classification } \\
\text { - Unwell reparation in providing care } \\
\text { - Lack of literacy of palliative care and family-centered } \\
\text { care }\end{array}$ & $\begin{array}{l}\text { "Patients who are no longer responding to chemotherapy are patients who are eligible for } \\
\text { palliative care ..." (P2) } \\
\text { "Actually, I don't really know about the FCC ..." (P3) } \\
\text { "... So, whether the FCC is a new intervention, I don't really understand (smile)" (P3) } \\
\text { "... FCC is a family-focused treatment, right?" (P5) }\end{array}$ \\
\hline $\begin{array}{l}\text { Ability to provide palliative } \\
\text { care and family-centered care }\end{array}$ & $\begin{array}{l}\text { - Improve communication skills } \\
\text { - The need for mutual awareness } \\
\text { - Strategies to provide greater benefit }\end{array}$ & $\begin{array}{l}\text { "In terms of patients, there are many patients, there are those who cry, some can be } \\
\text { cooperative, some don't want to (smile), some maybe have a psychological disturbed ..." (P1) } \\
\text { "... in terms of parents, there are parents who are complaining, there are parents who are } \\
\text { obedient, there are those who are basically cooperative..." (P3) } \\
\text { "... a palliative patient has been declared dead; our support is by for example finding an } \\
\text { ambulance..." (P5) } \\
\text { "We will still convey it to his family, then later in the hospital the old man must still convey it." } \\
\text { (P10) }\end{array}$ \\
\hline Multidisciplinary collaboration & $\begin{array}{l}\text { - Collaboration with others health-care professionals } \\
\text { - Involvement of others professions in providing care } \\
\text { - Role and function of each health-care professionals } \\
\text { - Respects to others } \\
\text { - Adaptation }\end{array}$ & $\begin{array}{l}\text { "... So, it is necessary, consultation or with a psychologist, some have reached a psychiatrist } \\
\ldots \text { ".. (P7) } \\
\text { "... every day, especially Tuesday and Friday, there are meetings to discuss patients between } \\
\text { doctors and nurses." (P2) } \\
\text { "Collaboration both with family and with other health workers well, we will try to work together } \\
\text { with such collaboration ..." (P4) } \\
\text { "... by means of nutrition, the nutrition that makes the program, for example, the doctor } \\
\text { calculates this fluid requirement ..." (P5) }\end{array}$ \\
\hline
\end{tabular}




\section{Discussion}

Results offered a valuable indicator of commitment on the part of nurses as to how to address the need and barrier prior providing palliative and FCC approach were, how the approaches were viewed by the participants and how much the nurses supported one another. Some concepts in this analysis are in line with other researchers' findings. Healthcare professionals find it difficult to work with diverse families - demanding, rude, or angry parents and parents who have conflicting opinions on treatment and palliative care - while conveying bad news to them [35]. The previous studies also highlight that palliative care pathways were vague, varied, and not readily recognizable; participants reflected on their experiences and perceptions of service delivery, such as lack of palliative care education, public knowledge, and adolescent-specific treatment, which presented a challenge in service delivery [36].

By incorporating FCC approaches, the current research found that there was no specific referral process for children with palliative care needs. Some health-care professionals did not believe that they were prepared to work with children with cancer, which is consistent with the results of Thompson et al. that confirmed that certain health-care professionals have differing abilities and lack trust in caring for children with cancer [37], [38]. Second, while the WHO considers palliative care as important in cancer treatment, this study found that certain health-care professionals do not generally hold that view. There are many potential causes for this outcome, including myths about palliative care. Cancer care workers matter-of-factly faced cancer mortality and palliative care as part of an endof-life treatment plan. Some practitioners also maintain some conventional palliative care principles. This result and its consequences are consistent with previous studies, which established a need for child cancer care palliative skills [39]. Furthermore, in Indonesia, there was limited access to pain management, especially opioid medicine. Cultural effects on pain perception have been previously identified, but further research is needed to establish the culturally appropriate treatment of symptoms such as pain [40]. Future research is required in Indonesia to offer more feasible policies regarding pain management, thereby fulfilling the WHO mandate to prevent and alleviate end-of-life misery in all children [41].

In a qualitative sample, the use of a small group is a constraint to allow the unfolding of a new and richly textured understanding of the phenomenon under study, which has been noted in the literature [42]. Non-generalizability of findings is also a drawback, as results could be institution specific or focus on setting of this study. This research primarily examined the opinions of health-care professionals; thus, results may be skewed toward the perspectives and expectations of health-care professionals. Nonetheless, all participants that were interviewed had taken care of children with cancer for a span of more than 2-3 years in some capacity.

\section{Conclusion}

The findings of this study suggest the need to incorporate FCC approaches in providing palliative care for children with cancer as well as the resources required for such programs to be implemented by hospital management in working toward improved quality care for patients. If this can be implemented, the result of incorporating palliative care for children with cancer will be a major endorsement to the call by the $76^{\text {th }}$ World Health Assembly for palliative care principles to be made an integral element in care for chronic illness. The theory primary nurses are less confident in caring for children with cancer through FCC approaches and palliative care; organizing and managing their treatment remain a challenge. Training and resources regarding palliative care and FCC will help equip health-care professionals with the skills and confidence to carry out FCC approaches and palliative care for children with cancer. Findings of this study could be a basic information for health-care professionals or policy-makers to develop and integrated FCC into palliative care by improving nurse' knowledge, ability, and their skill to work as multidisciplinary team.

\section{References}

1. Rodriguez-Galindo $C$, Friedrich $P$, Alcasabas $P$, Antillon $F$ Banavali S, Castillo L, et al. Toward the cure of all children with cancer through collaborative efforts: pediatric oncology as a global challenge. J Clin Oncol. 2015;33(27):3065. https://doi. org/10.1200/jco.2014.60.6376

PMid:26304881

2. Cavalli F, Atun R. Towards a global cancer fund. Lancet Oncol. 2015;16(2):133-4.

PMid:25638677

3. Gupta S, Rivera-Luna R, Ribeiro RC, Howard SC. Pediatric oncology as the next global child health priority: The need for national childhood cancer strategies in low-and middleincome countries. PLoS Med. 2014;11(6):e1001656. https://doi. org/10.1371/journal.pmed.1001656 PMid:24936984

4. Shulman LN, Mok TS. Special issue on global cancer medicine. $\mathrm{J}$ Clin Oncol. 2016;34(1):1-2.

PMid:26578609

5. Weaver MS, Yao AJ, Renner LA, Harif M, Lam CG. The prioritisation of paediatrics and palliative care in cancer control plans in Africa. Br J Cancer. 2015;112(12):1845-56. https://doi. 
org/10.1038/bjc.2015.158

PMid:26042935

6. Chan MH, Boop F, Qaddoumi I. Challenges and opportunities to advance pediatric neuro-oncology care in the developing world. Childs Nerv Syst. 2015;31(8):1227-37. https://doi.org/10.1007/ s00381-015-2771-x

PMid:26040936

7. Feudtner C, Kang TI, Hexem KR, Friedrichsdorf SJ, Osenga K, Siden $\mathrm{H}$, et al. Pediatric palliative care patients: A prospective multicenter cohort study. Pediatrics. 2011;127(6):1094-101. https://doi.org/10.1542/peds.2010-3225

PMid:21555495

8. Widger K, Davies D, Drouin DJ, Beaune L, Daoust L, Farran $\mathrm{RP}$, et al. Pediatric patients receiving palliative care in Canada: Results of a multicenter review. Arch Pediatr Adolesc Med. 2007;161(6):597-602. https://doi.org/10.1001/archpedi.161.6.597 PMid: 17548766

9. Pui $\mathrm{CH}$, Gajjar AJ, Kane JR, Qaddoumi IA, Pappo AS. Challenging issues in pediatric oncology. Nat Rev Clin Oncol. 2011;8(9):540-9. https://doi.org/10.1038/nrclinonc.2011.95 PMid:21709698

10. Association CHPC. Pediatric Hospice Palliative Care, Guiding Principles and Norms of Practice. Available from: https:// www.chpca.ca/product/pediatric-hospice-palliative-careguiding-principles-and-norms-of-practice-download/. [Last accessed on 2006 Oct 10].

11. World Health Organization. Definition of Palliative Care for Children. Geneva: World Health Organization; 2013.

12. Jones BL. Companionship, control, and compassion: A social work perspective on the needs of children with cancer and their families at the end of life. J Palliat Med. 2006;9(3):774-88. PMid:16752983

13. Kikule E. A good death in Uganda: Survey of needs for palliative care for terminally ill people in urban areas. BMJ. 2003;327(7408):192-4. https://doi.org/10.1136/bmj.327.7408.192 PMid:12881259

14. Harding R, Powell RA, Downing J, Connor SR, Mwangi-Powell F, Defilippi K, et al. Generating an African palliative care evidence base: The context, need, challenges, and strategies. J Pain Symptom Manage. 2008;36(3):304-9. https://doi.org/10.1016/j. jpainsymman.2008.04.008

PMid: 18722312

15. Ntizimira CR, Nkurikiyimfura JL, Mukeshimana $\mathrm{O}$ Ngizwenayo S, Mukasahaha D, Clancy C. Palliative care in Africa: A global challenge. Ecancermedicalscience. 2014;8:493. https://doi.org/10.3332/ecancer.2014.493 PMid:25624874

16. McGrath JM, Samra HA, Kenner C. Family-centered developmental care practices and research: What will the next century bring? J Perinat Neonatal Nurs. 2011;25(2):165-70. https://doi.org/10.1097/jpn.0b013e31821a6706 PMid:21540694

17. Eichner JM, Johnson BH, Betts JM, Chitkara MB, Jewell JA, Lye PS, et al. Patient-and family-centered care and the pediatrician's role. Pediatrics. 2012;129(2):394-404. https://doi. org/10.1542/peds.2011-3084

PMid:22291118

18. Perrin JM, Romm D, Bloom SR, Homer CJ, Kuhlthau KA, Cooley C, et al. A family-centered, community-based system of services for children and youth with special health care needs. Arch Pediatr Adolesc Med. 2007;161(10):933-6. https://doi. org/10.1001/archpedi.161.10.933

PMid:17909135

19. Kokorelias KM, Gignac MA, Naglie G, Cameron JI. Towards a universal model of family centered care: A scoping review. BMC Health Serv Res. 2019;19(1):564. https://doi.org/10.1186/ s12913-019-4394-5

PMid:31409347

20. Coats $H$, Bourget $E$, Starks $H$, Lindhorst $T$, Saiki-Craighill $S$, Curtis JR, et al. Nurses' reflections on benefits and challenges of implementing family-centered care in pediatric intensive care units. Am J Crit Care. 2018;27(7):52-8. https://doi.org/10.4037/ ajcc2018353

\section{PMid:29292276}

21. Meert KL, Clark J, Eggly S. Family-centered care in the pediatric intensive care unit. Pediatr Clin North Am. 2013;60(3):761-72. https://doi.org/10.1016/j.pcl.2013.02.011

PMid:23639667

22. Kaambwa B, Bryan S, Jowett S, Mant J, Bray EP, Hobbs FD, et al. Telemonitoring and self-management in the control of hypertension (TASMINH2): A cost-effectiveness analysis. Eur J Prev Cardiol. 2014;21(12):1517-30. https://doi. org/10.1177/2047487313501886

PMid:23990660

23. Kenner C, Press J, Ryan D. Recommendations for palliative and bereavement care in the NICU: A family-centered integrative approach. J Perinatol. 2015;35(1):S19-23. https:// doi.org/10.1038/jp.2015.145

PMid:26597801

24. Kissane DW. The challenge of family-centered care in palliative medicine. Ann Palliat Med. 2016;5(4):319-21. https://doi. org/10.21037/apm.2016.08.04

PMid:27806627

25. Gilmer MJ. Pediatric palliative care: A family-centered mode for critical care. Crit Care Nurs Clin North Am. 2002;14(2):207. https://doi.org/10.1016/s0899-5885(01)00013-2 PMid:12038509

26. Guyatt $G H$, Oxman $A D$, Vist GE, Kunz R, Falck-Ytter $Y$ Alonso-Coello P, et al. GRADE: An emerging consensus on rating quality of evidence and strength of recommendations. BMJ. 2008;336(7650):924-6. https://doi.org/10.1136/ bmj.39489.470347.ad PMid: 18436948

27. Putranto R, Mudjaddid E, Shatri H, Adli M, Martina D. Development and challenges of palliative care in Indonesia: Role of psychosomatic medicine. Biopsychosoc Med. 2017;11:29. https://doi.org/10.1186/s13030-017-0114-8 PMid:29201137

28. Rochmawati E, Wiechula R, Cameron K. Current status of palliative care services in Indonesia: A literature review. Int Nurs Rev. 2016;63(2):180-90. https://doi.org/10.1111/inr.12236 PMid:26751254

29. Tanaem GH, Dary M, Istiarti E. Family centered care pada perawatan anak di rsud soe timor tengah selatan. J Ris Kesehat. 2019;8:21

30. Bryman A, Burgess B. Analyzing Qualitative Data. London, United Kingdom: Routledge; 2002. https://doi.org/10.31983/jrk. v8i1.3918

31. Ritchie J, Lewis J, Nicholls CM, Ormston R. Qualitative Research Practice: A Guide for Social Science Students and Researchers. United States: SAGE; 2013.

32. Creswell JW, Fetters MD, Ivankova NV. Designing a mixed methods study in primary care. Ann Fam Med. 2004;2(1):7-12. PMid: 15053277

33. Braun V, Clarke V. Using thematic analysis in psychology. Qual Res Psychol. 2006;3:77-101.

34. Flick U. An Introduction to Qualitative Research. United States: Sage Publications Limited; 2018. 
35. Klassen A, Gulati S, Dix D. Health care providers' perspectives about working with parents of children with cancer: A qualitative study. J Pediatr Oncol Nurs. 2012;29(2):92-7. https://doi. org/10.1177/1043454212438405

PMid:22415857

36. Ngwenya N, Ambler J, Archary M. Qualitative situational analysis of palliative care for adolescents with cancer and HIV in South Africa: Healthcare worker perceptions. BMJ Open. 2019;9:023225. https://doi.org/10.1136/bmjopen-2018-023225

37. Thompson K, Dyson G, Holland L, Joubert L. An exploratory study of oncology specialists' understanding of the preferences of young people living with cancer. Soc Work Health Care. 2013;52(2-3):166-90. https://doi.org/10.1080/00981389.2012.7 37898

PMid:23521383

38. Davies S, Salmon P, Young B. When trust is threatened: Qualitative study of parents' perspectives on problematic clinical relationships in child cancer care. Psychooncology. 2017;26(9):1301-6. https://doi.org/10.1002/pon.4454

\section{PMid:28494129}

39. Snaman J, McCarthy S, Wiener L, Wolfe J. Pediatric palliative care in oncology. J Clin Oncol. 2020;38(9):954-62. https://doi. org/10.1200/jco.18.02331

PMid:32023163

40. Finley GA, Kristjánsdóttir Ó, Forgeron PA. Cultural influences on the assessment of children's pain. Pain Res Manage. 2009;14(1):33-7. https://doi.org/10.1155/2009/763031 PMid: 19262914

41. Downing J, Jassal SS, Mathews L, Brits H, Friedrichsdorf SJ. Pediatric pain management in palliative care. Pain Manage. 2015;5(1):23-35. https://doi.org/10.2217/pmt.14.45 PMid:25537696

42. Vasileiou K, Barnett J, Thorpe S, Young T. Characterising and justifying sample size sufficiency in interview-based studies: Systematic analysis of qualitative health research over a 15-year period. BMC Med Res Methodol. 2018;18(1):148. https://doi. org/10.1186/s12874-018-0594-7

PMid:30463515 